\title{
Faculty Burnout
}

Robert L. Minter, Executive Vice President/Chief Academic Officer, Walsh College

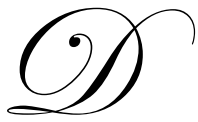

ysfunctional faculty performance behaviors related to stress are seldom openly discussed in professional circles, let alone with faculty members exhibiting these behaviors. If stress issues are discussed, they are often mentioned in a humorous vein with little, if any, solutions put forth to assist faculty who are experiencing aggravated stress that could easily lead to professional burnout.

There is little in the literature regarding stress as it relates to faculty burnout within the U.S. or internationally. Perhaps ideas represented here will encourage researchers to explore cultural similarities and differences that exist among those experiencing faculty burnout on an international level.

At this point in time, there are insufficient hard data and/or diagnostic research findings to explain burnout. It is difficult to determine whether burnout is simply a symptomatic behavior that will eventually "go away" over a period of time, or that there is a particular DNA that one has to cope with by utilizing stress management techniques. ${ }^{1}$

Faculty performance issues related to stress are often tolerated by the academic culture. These dysfunctional attributes, if gone unchecked, and not discussed with the stress victim, can easily become chronic and negatively impact other faculty, staff, students, and program quality. Faculty experiencing performance issues in meeting their professional responsibilities in the areas of teaching, scholarship, service, student-care -giving, and nurturing collegial relationships are likely candidates for the burnout zone. The irony is that university administrators frequently are reluctant to deal with the observable symptoms and behavioral issues associated with faculty burnout.

The term "burnout" comes from the language of aerospace in the 1950's and was then only used to describe fuel consumption of fuel in rockets and nuclear reactors. There was no allusion to human behavioral issues as part of the burnout definition during this period of time. One will not find the term "burnout" appearing in major dictionaries until 1966, when Webster's New World Dictionary for the first time defined burnout as: "Stop burning, for lack of fuel or to destroy by heat or friction." No allusion to human behavior existed in this definition.

Thirteen years later, the American Heritage Dictionary included the noun form "burn" to be defined both in technical and behavioral terms:

“... as a failure in a device attributable to burning, excessive heat or friction because of exhaustion or shutoff. To burnout is to become exhausted, especially as a result of overwork..." 2

Since then, varied definitions of "burnout" as they apply to human behavior have appeared in the literature. For example: ${ }^{3}$

- $\quad$ Burnout is when a person has pushed his/her creative energy beyond the point of discovery.

- Burnout is experiencing continuous job-related stress where one has the loss of physical, emotional and mental energy.

- Burnout is the lack of desire and motivation to achieve a balance among professorial responsibilities in the areas of: teaching, scholarship, service, and student care-giving and peer relationships.

- $\quad$ Burnout is when one experiences detachment (especially from students, staff, peers and clients) and a loss of satisfaction or sense of accomplishment.

- Burnout is fatigue, frustration, or apathy resulting from prolonged stress, overwork, or intense activity. (Webster's Universal College Dictionary, 2004)

- Burnout is neither a physical ailment nor a neurosis. It is a loss of will and inability to mobilize one's interest and capabilities. 


\section{WHY IS BURNOUT OCCURRING IN ACADEMIA?}

One author has referred to maneuvering along the faculty career path as "The Joyless Quest for Tenure. ${ }^{4}$ The total time to achieve the appropriate academic terminal degree including the time involved in advancing through the various faculty ranks of assistant/associate/full professor will take approximately 20 years. The critical path to academic professionalism can be time consuming, expensive, and for many, not all that financially rewarding.

After twenty years, faculty quickly realize that they have reached the "glass ceiling" of university promotional levels. For many, performance in research, service and student care tend to significantly level off or decline as part of the glass ceiling effect. This is often exhibited by their lower enthusiasm for involvement in activities within the university and/or college.

Faculty cultures within the United States have a tendency to thrive on rumor; cultivate cynicism towards students, other faculty, administration and staff personnel; emote more of a pessimistic rather than an optimistic point-of-view regarding the future of college/university programs to which they are employed, and become more critical of the system with advancing age.

With the passage of time, faculty tend to withdraw from professional activities and obligations associated with college and university life. Symptoms and anecdotes abound illustrating these kinds of behaviors. These behaviors can be viewed as symptomatic of "Academic Burnout," a concept that is seldom discussed among those of us associated within the "halls of ivy." Again, it must be emphasized that there are those select few in any college or university who are exemplary and do not fall into this behavioral trap.

The literature suggests that those who are directly involved in daily "helping professions" (such as university teaching) often expend a greater amount of emotional energy performing their daily responsibilities than do professionals interacting with "things" rather with people. It is also well recognized, that those in helping professions are prime candidates for burnout if they are not practicing energy management. ${ }^{5}$

An interesting paradox exists when one exams the literature on stress and faculty culture. Faculty, engaged in stress/burnout research, seldom discuss this phenomenon as it applies to those working within the university culture.

\section{UNIVERSITY ENVIRONMENT: A BREEDING GROUND FOR BURNOUT}

Faculty work within a unique service industry. It provides them with flex hours, participative decisionmaking opportunities, faculty governance, and a high degree of self-actualization. Surveys, however, indicate that there exists widespread dissatisfaction among faculty in a number of categories relative to their expectations of what the professional work environment should provide them. ${ }^{6}$

The following is usually the case when comparing stress and burnout in corporate life with those working in university environments:

- $\quad$ Stress and burnout related information is readily available to corporate level employees via pamphlets, selfhelp publications, corporate sponsored health clubs, stress workshops; employee counseling programs and corporate assistance centers. Corporate human resource departments are usually the providers of such information and assistance. This frequently is not the case for those employed in universities.

- $\quad$ There is more open discussion about stress factors in the corporate setting than there is in academic settings. Stress and related burnout issues often become closeted skeletons not to be discussed in academic settings.

- $\quad$ Corporate cultures have less tolerance for low performance behavior than do universities. In business a low performer can quickly loose a job within a "blink of the eye," if performance does not improve within a short time frame.

This is not the case in academia. In Universities, untenured, assistant professors are usually given 5 to 6 years to prepare for a tenure review decision based on performance in research, teaching and service. If 
tenure is not awarded, that individual is generally granted an additional year (i.e., a year of grace) to continue teaching and prepare for the final exit. Based on this model, it is common practice in university settings to find that a low performer will be tolerated for at least a 5 to 6 year window before that person is dismissed. The business sector does not accommodate this level of tolerance for marginal performers.

- $\quad$ Associate professors with tenure have at least another 5 or 7 years to enhance their dossier before they are reviewed for full professorship status. At most universities, faculty who receive associate professor rank with tenure do not have to be reviewed for full professorship until he/she determines to do so. Some associate professors who have been granted tenure may decide to stay within that rank in perpetuity due to their own decision to not fulfill the performance criteria required to advance to the full professor rank.

- $\quad$ Faculty who have been promoted to full professor rank may serve in that capacity without ever receiving an intensive post-tenure/full professor performance review by the university. Reviews (or lack of them) depend on individual university policy. If they are required, they are often conducted within a specific time period (e.g., every 3 to 5 years after holding the full professor rank).

Seldom do these reviews contain the intensity that a faculty member experienced when applying for associate or initial full professor rank. Full professors who receive unfavorable performance reviews are usually provided a "slap on the hand," and a performance improvement plan with the expectation that they do better prior to the next 3 to 5 year review period. If they do not live up to the performance plan, not much happens to them. Full professors who become marginal performers and show little improvement in any of the designated areas ( teaching, research, service) are well protected by the establishment even though they do not live up to the agreed upon performance improvement expectations.

When was the last time you heard of a tenured full professor being dismissed for low performance in any of the three hallowed categories mentioned above. In business, performance reviews and improvement plans are adhered to or one is quickly terminated.

- University environments nurture academic freedom and provide a professional life style that is unique to any other profession. University cultures provide faculty with the freedom to: decide what and how they will teach; recommend maximum class sizes (especially upper division courses);engage in faculty governance; control over pedagogy and selection of material to teach; establish student performance standards for their classes; negotiate for release time from teaching; set their own research agendas; create opportunities for self-actualization; benefit from an estimated thirty-two week work schedule (not including additional summer teaching); enjoy two-to-three days off for thanksgiving recess/ two to three weeks off for Christmas vacation/ five days off for spring break; teach or not teach during the summer months; have job security for life once tenure is received. Many of these perks are not available in the corporate sector. With all the above perks provided faculty, it is difficult for those outside the academic profession to understand the nature and existence of faculty burnout.

So, why is faculty burnout an issue for those working in an organizational culture, rich with perks and selfactualizing opportunities? Unfortunately, there are no simple answers to this question. University dynamics are extremely complex and contain multiple stressors for faculty to manage.

Experiencing faculty burnout does not come about all of a sudden. There is agreement in the literature that burnout happens in progressive stages over a period of time, such as the following: ${ }^{7}$

$\underline{\text { Stage } 1}$ Stress Arousal---This stage includes physiological and psychological responses that depict persistent irritability, anxiety, high blood pressure, insomnia, grinding of the teeth during sleep, heart palpitations, concentration difficulties, stomach problems and acute gastrointestinal symptoms. The article suggests that a faculty member experiencing any two of these may be experiencing Stage 1 burnout.

Stage 2 Energy Conservation --- The burnout candidate experiencing Stage 1 symptoms will often take measures to compensate for the stress one is experiencing. Denial that one has a problem is prominent at this stage. If these conservation measures fail to work for the individual, other behaviors prevail, such as: excessive lateness, procrastination, excessive absences, desire for sex, tiredness, withdrawal form friends and family, increased negativism, substance abuse (alcohol, prescription drugs, caffeine), apathy and depression. The CME report indicates that any two of these symptoms may indicate that one is in Stage 2 of the burnout cycle.

Stage 3 Exhaustion This is the stage where individuals begin to realize there is something chronically wrong with them. Chronic symptoms associated with this stage include: sadness or depression, stomach or bowel problems, 
mental fatigue. headaches, migraines, withdrawal from colleagues, friends and family, thoughts of suicide, and possible long term health problems. If gone unchecked these symptoms can lead to progressive disciplinary measures by the university for nonperformance. According to the report, experiencing at least two of these symptoms can indicate stage 3 burnout.

As the literature indicates, burnout is a process. It occurs in a sequentially slow and progressive pattern through the stages outlined above. Familiarity with the symptoms and dynamics associated with these stages can assist a faculty burnout victim to take steps to break the cycle.

\section{WHAT ARE THE STRESSORS LEADING TO BURNOUT IN ACADEMIC LIFE?}

There are many work related stressor events that can trigger burnout. Some of them are described below:

- $\quad$ Salary increases and merit pay are often too small to be effective long term motivators. Universities neither provide a great deal of monetary or nonmonetary recognition to faculty for their accomplishments. Salary increases and merit pay are often sporadic and cannot be assumed as givens on an annual basis. Salary raises, when provided, are usually within the $2 \%-4 \%$ range. Seldom do salary increases or merit pay keep up with inflation on an annual basis over a three to five year period.

- $\quad$ Faculty salaries in many university disciplines do not often justify the cost of obtaining academic degrees necessary for faculty careers in the halls of ivy. This is especially the case for those with doctorates in the humanities and education

- University retirement benefit packages are modest or less than modest in meeting individual economic needs.

- $\quad$ Open or lenient admission policies allow ill-equipped students to enter the classroom. Many incoming freshman lack basic survival skills in writing, speaking, math, critical thinking and problem solving ability. These students eventually become candidates for failure, with the hope that faculty members will perform miracles in upgrading student skill gaps within one or two semesters. The consequence is that faculty find themselves teaching down to the lowest skill level and GPA profile. In doing so, faculty begin demotivating the more talented students. It's no wonder that faculty often become frustrated because they are not intellectually challenged by the majority of their students, and often feel that they are not doing an effective job of teaching. Growing guilt feelings among faculty can create serious stress for those who pride themselves as good instructors.

- $\quad$ Faculty often feel that their academic freedom is eroding due to college administrators not providing them the courtesy of collegial discussion and involvement in solving university issues that impact classroom instruction.

- Junior faculty often work in an ambiguous environment containing unclear goals, fuzzy guidance on what one needs to do to obtain promotion and tenure, and often work in a culture that lacks a well-defined mentoring process for promotion and tenure.

- $\quad$ Faculty who have less than a terminal degree are often plateaued at a lesser rank with no opportunity to advance to the next higher rank without the doctorate or its equivalent.

- $\quad$ Tenure can serve as a job security blanket for marginal faculty who decide not to maintain their performance levels. Tenure can also become an enabler for those who decide to withdraw from meeting professional obligations.

- $\quad$ Career progression provides an inevitable glass ceiling for all faculties once they receive their full professorships. Promotional opportunities beyond a tenured full professor rank do not exist in U.S. universities unless one decides to pursue a university administrative position.

- University bureaucracy and stilted policies often subdue faculty and institutional innovation.

- $\quad$ Budget support for faculty development is often not sufficient for faculty to develop and expand their professional skill sets.

- $\quad$ Committee work is often perceived as unproductive with fruitless outcomes.

- Administrator expectations of faculty can be unrealistic in light of budget, resources and market competition. 
- $\quad$ Teaching loads at universities who primarily have a teaching mission are frequently more demanding (e.g., 4 courses per semester) than institutions who support lesser teaching loads due to release time for research or other service activities.

- Faculty loyalty is torn among professional values, university demands/expectations and union environments. Faculty loyalty is often given first to their profession and second to the university.

- There is a growing depersonalization among faculty with their university employers. Affiliation and loyalty to one's university should not be taken as a given.

- University strategic planning efforts can become activity traps for faculty involvement. Faculty often perceive these efforts as pseudo attempts by administration to make faculty feel like they are helping in the management of the university's strategic efforts.

- $\quad$ Receiving a number of publisher rejection slips over a period of time can become demotivators for faculty seeking tenure and promotion.

- $\quad$ Personal relationship issues not necessarily related to one's work.

Quantity and severity of stressors faculty experience over a period of time can easily entrap faculty into the "burnout cycle." Faculty caught-up in the burnout cycle will eventually exhibit dysfunctional professional behaviors leading to marginal performance in one or more of the responsibility areas of teaching, service, research, studentcare arenas and even in interpersonal relationships with their colleagues and family.

\section{HOW CAN BURNOUT BE IDENTIFIED?}

A precursor to burnout intervention is the ability for the victim, or an observer of one being victimized, to recognize the symptoms of burnout and the stages of the burnout cycle that have been previously mentioned. The following is an inventory of symptoms and behaviors that often correlate with burnout. No single item in the inventory should lead to the conclusion that one is in the burnout cycle. However, a cluster of symptoms often communicates that the individual may be experiencing some stage of burnout. Keep in mind that symptoms vary among burnout victims as well as do faculty behaviors while performing their responsibilities.

The following check list can be used as a self-inventory to determine where one is in terms of the various burnout stages. It can also be used to assess others to help understand their personal burnout dynamics and to engage in recovery discussions with impacted faculty.

There are no right or wrong answers to the inventory. It should be considered as a diagnostic tool. For each of the following, check those that apply to you or to the focal faculty member that you have in mind. For the brave ones, you can ask members of the faculty with whom you closely work to provide their perceptions about you by completing the inventory and discussing the results with you.

\section{BURNOUT CYCLE INVENTORY}

\section{Performance Related (Check those that apply)}

1 Y You often have feelings of anger toward others.

2 Y You easily become upset at meetings.

3 You feel that you are brighter, smarter, and more in tune with things than are your colleagues.

$4 \quad$ You frequently miss appointments.

$5 \quad$ You are frequently late for classes and meetings.

$6 \quad$ You are habitually late turning in grades.

$7 \quad$ You are habitually late submitting reports.

$8 \quad$ You habitually miss deadlines.

$9 \quad$ You find yourself being more negative than positive in your view of events.

10 Y You have a tendency to over eat.

11 You take on work assignments or committee work that do not challenge you.

12 Y You set unrealistic goals for yourself.

13 Y You have difficulty meeting goals and objectives. 
14 Y You find yourself conforming to a work culture that violates your personal values and code of ethics.

15 Y Your office is a mess. Materials are disorganized and scattered.

16 Y You are moonlighting (second job) to make ends meet.

17 Y You are noted to be a complainer.

18 You have a "short fuse" when dealing with others.

19 Y You frequently blame others when things go wrong.

20 _ You often experience frustration in the work setting.

21 Y Y You find that you have lost your tolerance for happenings around you that previously did not bother you.

22 _ You find that your hobbies, sport activities, and other outside interests are more enjoyable than engaging in those professional aspects of your job that you are being paid to do (e.g., teaching, research, service, student care-giving).

23. You are an obsessive workaholic.

24. The classroom experience is more of a demotivating than a motivating experience for you.

25. ___ You find that teaching and/or research are not fulfilling experiences for you.

26. ___ Students are not motivating you in the classroom.

27. ___ You feel holding office hours are not productive (a waste of your time).

28. ___ You do not enjoy advising students.

29. Y You feel that many students in your classes are not college material.

30. Y Y Y Y ou spend more of your time being critical of your students than you do talking about the "good ones" the high performers.

31. W When you are keeping office hours, the door is closed more often that it is open.

32. ___ You avoid initiating ideas at meetings.

33. Y__ You often display anger at those making demands of your time.

34. ___ You feel that most meetings you attend are a misuse of your time.

35. __ You harbor anti-sentiments toward most college administrators with whom you interact.

36. ___ Your grading is more severe than lenient.

37. ___ At least $70 \%$ of your final course grades are largely based on machine scored exams.

38. ___ Your attendance at meetings is less than stellar.

39. __ You wait until the last minute to prepare course syllabi and other course materials.

40. W When you read written student materials, your grading reflects more on the intent or substance than on the structural presentation (e.g., grammar, spelling, sentence structure).

41. ___ You have difficulty developing enthusiasm for teaching.

42. __ You have difficulty developing enthusiasm for engaging in intellectual activity (e.g., research, writing, publication).

43. You often feel that you've chosen the wrong profession.

44. _ Y You spend a minimal amount of time on campus.

45. __ Y Y Y ou do not enjoy working on teams or committees with your colleagues.

46. ___ You prefer to work alone as a professional rather than work on teams.

47. ___ You are looking forward to the day when you can retire.

48. ___ You often experience shortness of breath when in stress-related situations..

49. ___ You have an increasing number of student grievances or complaints regarding your teaching and/or professional behavior.

50. ___ You are not motivated to either begin and/or complete your terminal degree.

51. __ Y You are not happily married or satisfied with your current relationship.

52. ___ Domestic issues are interfering with your work.

53. You have continual financial issues to deal with.

54. ___ You are having an extra-marital affair.

\section{Heath Related (Check those that apply)}

55. ___ High blood pressure

56. ___ Diabetes

57. ___ Addictions (e.g., smoking, alcohol, other types of drugs)

58. ___ Over/underweight 
59. ___ Fatigue, tiredness

60. Emotionally drained

61. ___ Suicidal thoughts

62. _ Frequent headaches

63. __ Frequent mood swings

64. Chronic illness

65. ___ Depression

66. ___ Compulsive eater

67. ___ Psychologically absent even though physically present when interacting with others

68. ___ Low energy level

69. __ Out of physical shape

70. ___ Currently utilizing professional counseling services

\section{HOW CAN THE INTERVENTION AND RECOVERY PROCESS WORK?}

First of all, the burnout victim must recognize that he/she may be in a state of denial. The inventory above is an instrument that can help faculty develop an awareness and perspective regarding the stressors and phases of burnout that they may be experiencing. Through introspection, faculty can determine if they have a sufficient number of symptoms that need to be addressed and managed. Once denial is recognized, the individual is placed in a state of readiness to consider possible interventions to escape the various stages of the burnout cycle, such as the following:

- $\quad$ Recognize burnout symptoms regarding your performance, communication style, body language and attitudes.

- $\quad$ Be willing to make changes.

- $\quad$ Talk to someone: friend, counselor, family physician or clinic specializing in stress.

- $\quad$ Balance your life style and reprioritize what's important.

- $\quad$ Develop a management plan to overcome the stressors. Set goals and targets for change.

- Join stress management programs.

- $\quad$ Read about stress, burnout and suggested coping mechanisms.

- $\quad$ Negotiate with the Department Chair and Dean to temporarily "rewrite" your professional. responsibilities. Point out that your current professional responsibilities exceed your job description.

- $\quad$ Take a personal leave or sabbatical.

- $\quad$ Reverse your negative thinking and vocabulary.

- $\quad$ Explore relaxation exercises.

- $\quad$ Get a hobby

- $\quad$ Explore with the University's Human Resources Department about assistance in these matters.

In addition to the above, there is also an abundance of web site information that can assist one to work through the management of burnout. Burnout does not have to become a "disease." It can be viewed as a stage (s) that one is experiencing and can be reversed with the appropriate plan in place. As one author has said:

"The people who are most protected from burnout have a strong sense of self-expression, a good social support system, a confidant and a network of friends. They accept their own talents without being egotistical. It's important to laugh. If one is in an environment where he/she can't sometimes be light, the gloom and solemnity will drag on the spirit."

\section{AUTHOR INFORMATION}

Dr. Minter is currently Executive Vice President and Chief Academic Office and professor at Walsh College, Troy, MI. He has been a Dean of Business Colleges at: Delaware State University, Texas Wesleyan University, Cleveland State University, University of Northern Iowa, University of Michigan-Dearborn and Central Connecticut State University. 
He has a Ph.D. in Organizational Communication and Industrial Relations from Purdue University. Both his Master of Arts and Bachelor of Arts Degrees are from Miami University of Ohio.

\section{FOOTNOTES}

${ }^{1}$ Kauffman, Kristina. (December 22, 2004). "How to Avoid Burnout.” http://www.4faculty.org.

${ }^{2}$ Briscoe, Mary Louise. (Winter 1984). "Reflections On Academic Burnout." ADE Bulletin, 079, pp.1-7.

${ }^{3}$ Smith, Earl. (1992). "A Comparative Study of Occupational Stress in African American and White University Faculty." E. Mellon Press; Potter, Beverly A. (1980). Beating Job Burnout. San Francisco: Harbor Publishing, Inc. ${ }^{4}$ Perlmutter, David. (November 30, 2007). "The Joyless Quest for Tenure.” Chronicle of Higher Education, pp. 1-4.

${ }^{5}$ Berman, Mark. (Spring 1995). "Psychologist Mark Berman on Burnout." ASTD InfoLine (American Society for Training and Development), pp.1-2

${ }^{6}$ AACSB International Newsline. (Fall 1999). aacsb.edu/publications/printnews NL 1999/wnfinding; BFA Administrator Appraisal Report: Colorado. edu/FacultyGovernance/STCOM/ADMAPC; Terpstra, David and Honoree, Andre L. (Spring 2004). "Job Satisfaction and Pay Satisfaction Levels of University Faculty By Discipline Type and By Geographic Region.” CNET Networks, Inc.

7,"Burnout." (February 7, 2005). CME publication at http://www.texmed.org/cme/phn/psb/burnout.asp. pp. 1-2 ${ }^{8}$ Musick, Janine Latus. (April 1997), "How Close Are You to Burnout?" Family Practice Management. http://www.aafp.org/fpm970400fm/lead.html pp. 1-8. 